\title{
FRONTEIRA E QUESTÃO AGRÁRIA NO BRASIL
}

\author{
Frontier and agrarian question in Brazil \\ Frontera y cuestión agraria en el Brasil
}

\section{João Edmilson Fabrini}

Doutorado em Geografia pela Faculdade de Ciências e Tecnologia - Unesp - Presidente Prudente. Docente na Universidade Estadual do Oeste do Paraná - Unioeste.E.mail: fabrini2@hotmail.com

\section{Resumo}

A fronteira é espaço de limite entre territórios forjado no processo contraditório e desigual de expansão das relações sociais de produção. Ela possui características gerais e particulares que se articulam entre si. São características do espaço agrário de fronteira no Brasil as ilegalidades na apropriação de terra, ausência do Estado, utilização de terras para fins especulativos, trabalho análogo à escravidão, luta pela terra e atuação de movimentos sociais camponeses, dentre outras. A partir dessas características verificadas na fronteira é possível afirmar que existe uma "questão agrária de fronteira no Brasil".

Palavras-chave: questão agrária, território, fronteira.

\begin{abstract}
The frontier is space boundary between forged in contradictory and uneven process of expansion of the social relations of production territories. It has general and special features that are mutually interconnected. Are characteristics of the agricultural frontier in Brazil space illegalities in land appropriation, absence of the rule, use of land for speculative purposes, work similar to slavery, the struggle for land and acting peasant social movements, among others. From these characteristics established at the border is possible to affirm that there is an "agrarian question in Brazil border."
\end{abstract}

Keywords: agrarian question, territory, frontier.

\section{Resumen}

La frontera es espacio de límite entre territorios forjado en el proceso contradictorio y desigual de expansión de las relaciones sociales de producción. Ela tiene características generales y particulares que están interconectadas entre sí. Son características de la frontera agraria en el Brasil las ilegalidades en la apropiación de la tierra, la ausencia del Estado, el uso de tierras con fines especulativos, trabajo comparable a la esclavitud, lucha por la tierra y actuación de los movimientos sociales campesinos, entre otros. A partir de estas características en la frontera es posible afirmar que existe una "cuestión agraria de frontera en el Brasil”.

Palabras clave: cuestión agraria, territorio, frontera. 


\section{INTRODUÇÃO}

O tema fronteira é investigado na geografia desde passado distante, quando esta ciência surgiu no final do século XIX. Nessa trajetória de investigação, a geografia interpretou a fronteira a partir de parâmetros teórico-metodológicos diversos, o que implicou em diferentes abordagens e compreensões.

O paradigma positivista hegemônico na geografia brasileira até a década de 1970, caracterizado pela abordagem empírica, descritiva e natural, não permitiu interpretar a fronteira no contexto da expansão contraditória e desigual do modo capitalista de produção. Dessa forma, não foi possível visualizar a existência de um problema agrário estrutural na fronteira, ou seja, não considerou a existência de uma questão agrária de fronteira no Brasil. Mas, um problema agrário estrutural estava presente no espaço fronteiriço brasileiro.

O espaço de fronteira possui características gerais e particulares. São características do espaço agrário de fronteira no Brasil as ilegalidades na apropriação de terra, ausência do Estado, utilização de terras para fins especulativos e acumulação rentista de capital, existência trabalho de análogo à escravidão, luta pela terra e atuação de movimentos sociais camponeses, dentre outras. Essas características permitem afirmar que existe um problema agrário típico de fronteira, ou seja, uma questão agrária de fronteira no Brasil.

\section{0 espaço de fronteira}

A fronteira é tema de investigação da geografia desde passado distante, quando essa ciência surgiu no final do século XIX. Os estudos de geografia política de F. Ratzel, por exemplo, abordavam a fronteira na perspectiva da expansão territorial, do solo da nação. Na sua trajetória de investigação, a geografia interpretou a fronteira a partir de parâmetros teórico-metodológicos diversos, o que implicou em diferentes abordagens e compreensões.

Atualmente, no contexto da globalização do mercado capitalista, verifica-se, de um lado, a flexibilização de fronteiras e, de outro, num sentido oposto, observa-se o estabelecimento ou reforço de fronteiras, principalmente nacionais. Assim, no contexto de expansão contraditória e desigual das relações capitalistas de produção, algumas fronteiras são derrubadas e outras são erguidas. Nesse processo, ora são hegemônicas as forças político-estatais, ora as forças econômicas ou ainda as forças populares, capazes também de delimitar, desfazer ou refazer fronteiras. 
Neste sentido, o território necessita sempre de algum tipo de fronteira, embora a gente vivesse um tempo, dos anos 1990 para cá, em que muitos discursos foram feitos em nome do debilitamento das fronteiras. Mas, aí o que a gente vê hoje, quase um sentido oposto, é um fortalecimento dos muros, das cercas, das fronteiras num sentido mais extremo. (HAESBAERT, 2009, p. 57).

A fronteira geográfica é aquela existente entre territórios. Os territórios são espaços sob domínio, controle e poder de um indivíduo, categoria ou classe social. A faixa mais ou menos ampla de limite entre os territórios forma o espaço de fronteira que pode ser entre territórios nacionais ou internos à nação. Nesse sentido, pode existir fronteira entre nações, unidades político-administrativas internas à nação ou ainda aquelas que não delimitadas pelas forças político-estatais, como a fronteira entre o território camponês e o território do agronegócio latifundiário, por exemplo.

A abordagem da fronteira entre territórios pode se sustentar no conceito de "fronteira em movimento". Esse conceito foi cunhado por Turner (2004) para referir-se à ocupação de novas áreas, no caso, a ocupação do Oeste dos Estados Unidos (EUA) da América. Portanto, será nessa perspectiva territorial e de movimento a abordagem de fronteira e da questão agrária nela implícita.

De acordo com Turner (2004), a fronteira é livre e democrática, pois não está sujeita diretamente ao controle do Estado. A ausência estatal significaria presença de democracia. Segundo o autor, a fronteira seria democrática também porque se constitui numa possibilidade e oportunidade abertas à reprodução da agricultura camponesa. O Homestead Act, por exemplo, permitiu acesso à terra aos pequenos agricultores na ocupação do Oeste norte-americano. Assim, essa fronteira livre para a reprodução da pequena agricultura se constituiu numa fronteira essencialmente agrária.

A formação democrática da sociedade norte-americana, inclusive, teria sido forjada a partir da fronteira (Oeste) e não da costa atlântica (Leste). Velho (1979), no seu estudo sobre Capitalismo Autoritário e o Campesinato, afirma que, "na verdade, a chamada 'Tese de Turner' (Turner thesis) envolve não só a fronteira per se, mas a partir da perspectiva da influência da fronteira sobre a sociedade" (p.16).

Velho (1979) ainda, ao tratar de "fronteira em movimento", menciona o caso brasileiro, embora alerte que a utilização desse conceito não deve ser uma transferência automática. Ele destaca também a "fronteira em movimento" abordando sobre a ocupação com a Plantations açucareira e sua decadência em relação ao Centro-Sul, a importância da cultura cafeeira, o regime oligárquico autoritário e a marcha para o Oeste na segunda metade do século XX, principalmente. A fronteira ligada à expansão do café na marcha para 
o Oeste evidencia característica essencialmente agrária à ocupação das novas terras. Por isso, a fronteira é local de expansão da agricultura e incorporação do potencial agrícola à dinâmica nacional. A cidade e a urbanização vêm depois, em função da dinâmica agrária existente naquele espaço ${ }^{1}$.

Ao analisar comparativamente a fronteira amazônica e a norte-americana, Velho (1979) elaborou crítica à ideia de fronteira democrática. O autor afirma que na fronteira amazônica não se fortaleceu um capitalismo burguês pela via Farmer, como nos EUA, mas um capitalismo autoritário, que recorre às relações não-capitalistas como a latifundiária e a violência para se reproduzir, contrastando-se com um modelo clássico de acumulação capitalista.

Assim, enquanto Turner (2004) interpreta a fronteira como democrática, Velho (1979) a interpreta como autoritária. Mas, tanto Turner (2004) quanto Velho (1979) entendem a fronteira no contexto do movimento e vinculada ao processo geral de acumulação capitalista, pois ela recebe excedente de força de trabalho, investimento de capital e fornece matéria-prima e alimentos aos espaços "consolidados", etc.

Foweraker (1982), ao tratar da economia política da fronteira, refere-se às etapas do processo de ocupação da terra com a transição das relações não-capitalistas para a pré-capitalista e posteriormente a capitalista, exemplificando o caso do Paraná, Mato Grosso do Sul (ainda não criado como uma unidade da federação), Mato Grosso e Pará. Segundo Foweraker (1982), o estágio não-capitalista é caracterizado pelo extrativismo, baixa renda, subsistência, comércio de pequenas mercadorias, aviamento e a terra com pouco valor comercial. O estágio pré-capitalista é marcado por migrações, extrativismo comercial, mercado inicial de terra e conflitos entre empresa e campesinato. O estágio capitalista apresenta mercado de terras, sendo que o documento define sua posse, laços fortes com economia nacional, rodovias e o trauma (violência) da passagem da fase anterior para a capitalista. Mas o autor observa que, em vista da estrutura heterogênea da sociedade brasileira, diferentes modos de produção existem lado a lado e a transição de uma etapa para a outra jamais pode vir a ser completada.

A partir de autores como Waibel (1979), Monbeig (1984), Martins (1975), Pereira (1990), dentre outros, é possível relacionar fronteira com a concepção de "frente", no caso, "frente pioneira" e "frente de expansão".

\footnotetext{
Santos (1993) entende que o espaço da fronteira amazônica já nasceu urbanizado em função dos processos produtivos aí
} existentes. O meio técnico-científico e a globalização fizeram a fronteira surgir urbanizada. 
A “frente de expansão" está relacionada ao avanço da população - uma frente demográfica para a qual o acesso a terra não foi pela compra - ao interior, isto é, para frente, buscando terra desocupada para abrir uma posse. A "frente de expansão" situa-se entre o domínio do fazendeiro e a sociedade tribal. Sua economia não pode ser classificada como natural, pois o excedente aí produzido está integrado ao valor de troca. No entanto, as relações não são determinadas pela produção de mercadorias.

A "frente pioneira" vem num segundo momento, depois da "frente de expansão", quando as relações capitalistas tornam-se imperativas no espaço e avançam sobre as terras dos posseiros. Na "frente pioneira" verifica-se a propriedade privada da terra (concebida como mercadoria e adquirida por meio de compra) e a incorporação à economia de mercado, semelhante ao agronegócio que avança sobre as terras camponesas. Mas, em muitos casos, a fronteira econômica (pioneira) vai adiante da frente demográfica (expansão), verificada na especulação de terras, por exemplo, a ser tratada posteriormente.

Segundo Martins (1975), existe um choque entre a "frente pioneira" e a "frente de expansão" quando ocorre o avanço e a intensificação das relações capitalistas no novo espaço para o capital ${ }^{2}$. O encontro da "frente pioneira" e da "frente de expansão" faz a fronteira um espaço essencialmente conflituoso, sobretudo conflitos pela posse da terra. São exemplares os conflitos resultantes da expansão da agricultura empresarial capitalista (agronegócio) sobre territórios indígenas e camponeses-posseiros.

Mas, a fronteira não é espaço somente de conflitos e se verifica também encontros, agregações e interações a partir da condição social dos sujeitos que forjam movimentos sociais de luta pela terra, por exemplo. Tais encontros, agregações e interações a partir da condição social são diferentes do suposto "hibridismo cultural" desclassificado (que não considera classes sociais) de fronteira.

\section{A questão agrária brasileira e a geografia}

Enquanto a fronteira é tema de investigação da geografia desde passado distante no final do século XIX, a questão agrária se constituiu num temário de estudo na década de 1970, quando essa ciência passou por um processo de renovação com a introdução de conceitos e pressupostos teórico-metodológicos marxistas.

A questão agrária pressupõe a existência de um problema estrutural no campo, do qual se destaca a apropriação desigual das terras e o controle do processo de acumulação

Martins (1975) tece crítica à interpretação de frente pioneira feita pelos geógrafos, pois segundo o autor, esses consideram vazio o espaço onde não estão presentes relações capitalistas de produção. 
de capital feito pelos proprietários fundiários e capitalistas. No Brasil, a concentração da propriedade da terra se constitui no nexo fundante da questão agrária.

Os dados do IBGE (Instituto Brasileiro de Geografia e Estatística) e do Incra (Instituto Nacional de Colonização e Reforma Agrária) na tabela a seguir (tabela 1), organizada por Oliveira (2011), indica a trajetória recente de concentração da posse da terra no Brasil. Nessa trajetória houve a intensificação e agravamento da concentração da terra no país.

\section{Índice de Gini - apropriação da terra (Brasil) Tabela 1}

\begin{tabular}{c|c} 
Ano & Índice \\
\hline 1950 & 0,840 \\
\hline 1960 & 0,039 \\
\hline 1970 & 0,843 \\
\hline 1975 & 0,854 \\
\hline 1980 & 0,857 \\
\hline 1985 & 0,857 \\
\hline $1995 / 6$ & 0,856 \\
\hline 2006 & 0,854 \\
\hline
\end{tabular}

Fonte IBGE; in: Oliveira (2011).

Os dados do censo de 2006 do IBGE indicam que 0,91\% de grandes estabelecimentos acima de 1.000 hectares detêm mais de $44 \%$ das terras no Brasil, enquanto $47,8 \%$ de pequenos estabelecimentos de até 10 hectares ocupam apenas 2,3\% da área total.

Na tabela a seguir (tabela 2), organizada por Teixeira (2011), verifica-se um aumento da participação dos grandes imóveis na área total. Se em 2003 as grandes propriedades detinham 51,6\% da área total, em 2010 passaram a deter 56,1\%. Enquanto isso, as pequenas propriedades sofreram uma redução na participação, pois diminuíram de 17,8\% para $15,6 \%$ (p. 5) nesse mesmo período. Verifica-se ainda uma diminuição das áreas produtivas de grandes propriedades de $37,7 \%$ para $28,3 \%$, indicando elevação da ociosidade da terra das grandes propriedades.

\section{Indicadores comparativos Tabela 2}

\begin{tabular}{l|c|c|c|c}
\hline \multicolumn{1}{c|}{ Categoria } & $\begin{array}{c}\text { Participação } \\
\text { área - 2003 }\end{array}$ & $\begin{array}{c}\text { Participação } \\
\text { área - 2010 }\end{array}$ & $\begin{array}{c}\text { Variação } \\
\text { Part. área }\end{array}$ & Variação área \\
\hline Minifúndio & $9,4 \%$ & $8,2 \%$ & $-12,3 \%$ & $19,8 \%$ \\
\hline Pequena propriedade & $17,8 \%$ & $15,6 \%$ & $-12,4 \%$ & $19,7 \%$ \\
\hline Média propriedade & $21,2 \%$ & $20,0 \%$ & $-5,3 \%$ & $29,3 \%$ \\
\hline Grande propriedade & $51,6 \%$ & $56,1 \%$ & $8,7 \%$ & $48,4 \%$ \\
\hline Grande produtiva* & $37,7 \%$ & $28,3 \%$ & $-24,9 \%$ & $11,5 \%$ \\
\hline
\end{tabular}

*Refere-se à participação nas respectivas áreas totais das grandes propriedades

Fonte: Incra; In: Teixeira (2011). 
Alguns autores, tais como Delfim Neto, Ruy M. Paiva e Antônio B. de Castro, na década 1970, e, mais recentemente, Xico Graziano, entendem que não existe um problema estrutural na agricultura brasileira relacionado à apropriação da terra que possa se caracterizar como uma questão agrária. Na compreensão de Xico Graziano (2004), se existiu um problema agrário, isso foi no passado, quando havia imensas áreas de terra improdutivas. Atualmente, com a modernização da agricultura e a emergência de empresas rurais de agronegócio, não existem terras latifundiárias improdutivas e por isso não há um problema agrário estrutural derivado da apropriação concentrada da terra. Os problemas existentes no passado foram resolvidos com ajustes no sistema produtivo sem necessidade de alterações na estrutura da propriedade da terra, o que fez do Brasil uma potência produtiva agrícola.

Entretanto, movimentos sociais camponeses, estudiosos, partidos políticos, organismos internacionais como a Comissão Econômica para a América Latina e o Caribe (Cepal), dentre outros, guardadas as suas diferenças, defendem desde passado recente a realização da reforma agrária como uma medida para solucionar a questão agrária e o problema da concentração fundiária no Brasil. A realização da reforma agrária foi vista pela Cepal, partidos políticos e, inclusive, pelos movimentos camponeses como uma necessidade para o desenvolvimento do Brasil e não somente uma necessidade dos pobres despossuídos da terra.

O discurso desenvolvimentista nacional passou a sustentar e justificar muitas das ações dos movimentos sociais, pois a capacidade produtiva camponesa teria papel importante no país, inclusive de soberania, no caso alimentar. Assim, o lugar social dos camponeses e da pequena agricultura seria garantido pela sua eficiência e capacidade produtiva de alimentos e matérias-primas para atender à demanda da nação brasileira.

O MST (Movimento dos Trabalhadores Sem Terra), por exemplo, por meio da palavra de ordem "reforma agrária: uma luta de todos", entende que toda a sociedade, e não somente os sem-terra, se beneficiarão da realização da reforma agrária. Esse benefício se deve à capacidade e à eficiência produtiva da pequena agricultura, sobretudo à produção de alimentos para toda a sociedade.

A capacidade produtiva dos pequenos agricultores é verificada a partir de dados oficiais da área cultivada, produção e financiamentos para investimento e custeio de lavouras. Os pequenos agricultores, dispondo de apenas $24,3 \%$ da área total de terras do país, conforme o IBGE (2006), e de R $\$ 26$ bilhões em recursos financeiros (Plano Safra da Agricultura Familiar 2013-2014), são responsáveis por 33\% do PIB (Produto Interno Bruto) 
agropecuário. Eles produzem 100\% das verduras, $87 \%$ de mandioca, $70 \%$ do feijão, 59\% de suínos, $58 \%$ do leite, $50 \%$ de aves, $46 \%$ do milho, $38 \%$ do café, dentre outros exemplos. Acrescenta-se que as pequenas propriedades empregam $74,4 \%$ dos trabalhadores e ocupam 15 pessoas a cada 100 hectares. A agricultura empresarial - agronegócio - tem à sua disposição $\mathrm{R} \$ 136$ bilhões, sendo R \$97,6 bilhões para custeio e comercialização e R \$ 38,4 bilhões para investimento, mas emprega apenas 25,6\% dos trabalhadores e ocupa somente 1,7 pessoas a cada 100 hectares.

Embora a concentração da posse da terra estivesse presente no Brasil desde passado colonial, bem como os conflitos derivados dessa concentração, ela não constituiu numa temática forte de estudo da maioria dos geógrafos agrários brasileiros até a década de 1970. Nesse contexto, a reforma agrária também não se constituiu numa problemática fundamental da geografia brasileira e os estudos dos geógrafos não tiveram penetração no debate sobre a questão agrária hegemonizado pelas ideias marxistas.

Waibel (1979) foi um geógrafo que se dedicou aos estudos rurais e teve grande influência no pensamento geográfico brasileiro para a interpretação do espaço agrário até a década de 1970. Ele procurou descrever as diferenças espaciais na agricultura a partir da colonização e os sistemas agrícolas adotados pelos colonos no Sul do Brasil, principalmente. O autor defendia a necessidade de formação de colônias de acordo com a cultura e religião, pois a mistura de etnias e costumes poderia ser um obstáculo para o progresso social e econômico da população rural.

A partir dos aspectos econômicos que caracterizavam a paisagem das colônias, Waibel (1979) formulou o conceito "minimale ackennahrung", ou seja, uma relação entre quantidade mínima de terra e sistema agrícola capaz de proporcionar à família do agricultor um padrão de vida adequado. De acordo com o autor ainda, os lotes coloniais deveriam ser entre 55 e 65 hectares em terra de boa qualidade e entre 80 e 105 hectares em "terras ruins".

O problema do tamanho adequado das propriedades é vital para qualquer projeto de colonização, e deveria ser estudado cuidadosamente de todos os ângulos, antes de ser iniciada a colonização. Para a compreensão do problema, desejo apresentar-lhe a expressão alemã minimale ackernahrung; refere-se ela à mínima quantidade de terra necessária para proporcionar a um agricultor e sua família um padrão econômico e cultural decente". (WAIBEL, 1979, p. 257)

Outra concepção de Waibel incorporada aos estudos de geografia agrária foi a de zona pioneira, considerada a área situada entre a floresta e a "civilização". Esta área é caracterizada pela presença do "frontiersman", com a introdução de melhoramentos técnicos. Ao tratar de zona pioneira como uma fronteira, sua abordagem não tratou de forma exAo tratar de zona pioneira como uma fronteira, sua abordagem não tratou de forma ex- 
plícita sobre a existência de uma questão agrária, no caso, questão agrária de fronteira, bem como das relações sociais e suas contradições engendradas no modo de produção modo de produção capitalista.

Outros geógrafos importantes se ocuparam nos estudos agrários, como foi o caso de Monbeig (1984), que veio compor o quadro de docentes de Geografia na USP (Universidade de São Paulo), na década de 1930. Dentre outros estudos, o autor tratou dos fazendeiros e pioneiros de São Paulo. Monbeig (1984), assim como Waibel (1979), embora tivessem olhares centrados no progresso e desenvolvimento econômico moderno, não se atentavam para os conflitos intrínsecos às relações sociais de produção que pudessem caracterizar a existência de uma questão agrária.

George $(1965,1982)$ foi outro autor que influenciou na constituição da geografia agrária brasileira, ao tratar do espaço agrário no contexto da geografia econômica. A interpretação de George $(1965,1982)$ estava assentada na descrição de diferenciações agrícolas e, embora buscasse fundamentação em autores que adotavam ideias anarquistas e socialistas utópicas, as relações sociais de produção eram abordadas de modo descritivo. A matriz teórico-metodológica continuava baseada no empirismo, o que dificultava a abordagem e visualização de problemas estruturais, como a posse concentrada da terra e os conflitos dela derivados, por exemplo.

Entretanto, desde passado distante, alguns autores da geografia aproximavam-se de concepções que permitiam visualizar a existência de um problema agrário. Este foi o caso de Elisée Reclus e Piet Kropotkin, no final do século XIX e início do XX. Segundo Andrade (1987), E. Reclus e P. Kropotkin receberam influência da dialética e trouxeram para discussão a categoria de classes sociais nos estudos geográficos.

Estes dois geógrafos libertários, Reclus e Kropotkin, apesar de positivistas, receberam forte influência dialética, citando frequentemente Marx e aceitando a categoria classe social no estudo da geografia; escreveram livros e artigos explícitos de doutrinação e propaganda política contra a sociedade estabelecida ao lado de livros especificamente geográficos. (ANDRADE, 1987, p. 61)

E. Reclus, por exemplo, a partir do princípio anarquista e libertário, preocupou-se com temas como a divisão da sociedade em classes em consequência da apropriação desigual dos meios de produção, dominação colonial, degradação do meio ambiente, problemas das grandes aglomerações e industrialização. Segundo Campos (2012), E. Reclus, na sua obra principal "L'homme et la Terre", publicada em 1905, atentava para a apropriação desigual das terras na Europa Ocidental, afirmando que a concentração de terras era res- 
ponsável pela exclusão, exploração e conflitos sociais. Mas o pensamento anarquista pouco influenciou os geógrafos brasileiros a conceber e reconhecer a existência de um problema agrário no Brasil.

A aproximação de uma discussão na geografia brasileira que permitisse reconhecer a existência de um problema agrário estrutural ocorreu a partir dos estudos de Valverde (1985), principalmente. Embora a geografia do autor apresentasse traços descritivos em que o geógrafo agrário, o "agrogeógrafo", devia levantar informações minuciosas da área estudada, sua abordagem procurava comprovar no campo brasileiro um problema relacionado ao processo de formação da estrutura agrária. Valverde (1985), apesar de seguir pressupostos de L. Waibel, não se dedicou a compreender os sistemas agrícolas apenas, mas também as "formações econômicas", ressaltando maior conteúdo político ao referir-se às contradições do espaço agrário brasileiro.

Outros autores como Andrade (1980), Petrone (1974) e Seabra (1977) também contribuíram para consolidar a questão agrária no temário da geografia brasileira. Eles enfatizavam nos seus estudos as condições de vida dos camponeses, colocando no centro de suas interpretações o contexto socioeconômico e a maneira como a terra estava apropriada, referindo-se, inclusive, à necessidade de realização de reforma agrária.

Na década de 1970, a modernização da agricultura e as mudanças técnicas nas relações de produção fizeram os geógrafos buscarem novos caminhos teórico-metodológicos. Foram feitas abordagens na geografia agrária a partir do paradigma da geografia teorética na qual se destacaram Diniz (1984), Ceron e Girardi (1979), dentre outros. O uso de novos conceitos, técnicas, métodos e modelos estatístico-matemáticos na geografia agrária possibilitou estudos de tipologia agrícola com auxílio da estatística, forjando uma geografia agrária de caráter pragmático e de resultados. Nesta compreensão, a geografia agrária também não visualizou uma questão agrária porque sua preocupação estava centrada na elaboração de ferramentas que pudessem ser instrumentalizadas e aplicadas na compreensão do espaço rural e não nas relações sociais de produção.

A visualização de uma questão agrária pelos geógrafos tomou maior corpo e força no contexto de surgimento da "geografia crítica" com estudos de Andrade (1980), Bray (1987), Oliveira (1979, 1981, 1991, 2007), dentre outros. Destacam-se os estudos de Oliveira $(1979,1981,1991,2007)$, que abordou o espaço agrário na perspectiva do desenvolvimento desigual e contraditório do modo de produção capitalista, ou seja, a partir do entendimento de que o capitalismo nega e reproduz relações não-capitalistas de produção. 
O autor introduziu um conjunto de conceitos do materialismo dialético nos estudos de geografia agrária, tornando-se um dos principais representantes desta corrente, ao se preocupar com os conflitos, posse, concentração e especulação de terras para obtenção de renda, subordinação e expropriação do campesinato, movimentos sociais, território, dentre outros. Acrescenta-se à interpretação da questão agrária brasileira do autor os conceitos de “territorialização do capital" e "monopólio do território". A territorialização do capital pode ser verificada nas empresas de agronegócio como usinas de açúcar e destilaria de álcool, principalmente. A monopolização do território se expressa na presença de empresas como Brasil Foods, Perdigão, Bunge, dentre outras, no setor agropecuário, que não se apropriam de terras, mas possuem controle e domínio do espaço (monopólio do território) na circulação da produção camponesa.

A partir da interpretação de Ariovaldo U. Oliveira, muitos outros autores deram contribuição para compreender a questão agrária no Brasil. Neste contexto se fortaleceu na abordagem da questão agrária uma categoria essencialmente geográfica: o território. A dimensão e a categoria território tomaram corpo na geografia e fora dela, a partir de diferentes perspectivas. Mas aquela que se constituiu como base para o pensamento do território na geografia foi a elaborada por Raffestin (1993), ao tratar da geografia do poder.

\section{A questão agrária na fronteira}

O espaço de fronteira no Brasil é forjado no contexto desigual e contraditório do modo capitalista de produção, quando um processo geral se realiza num quadro territorial menor. Portanto, no espaço de fronteira se reproduzem características gerais do modo de produção.

São características gerais das relações capitalistas de produção na fronteira, por exemplo, a exploração da força de trabalho assalariada por empresas (empreiteiras) privadas que atuam na construção de hidrelétricas no Brasil. Em 2011 ocorreram diversos conflitos entre trabalhadores assalariados e empresas, como a Camargo Corrêa, Suez Energy, Andrade Gutierrez, Odebrecht, Galvão Engenharia, dentre outras, que constroem a usina de Santo Antônio no Rio Madeira, em Rondônia.

Mas, o espaço de fronteira possui características particulares e típicas que interferem favorecendo (ou desfavorecendo) o processo de acumulação de capital. Dentre as características típicas do espaço agrário da fronteira é possível destacar a apropriação ilegal de terras; acumulação rentista com a utilização de terras para fins especulativos; trabalho degradante análogo à escravidão, resistências e lutas camponesas e indígenas nos movimentos sociais; ausência do Estado; dentre outras. Essas características, combinadas desigual 
e contraditoriamente uma à outra, e ao processo geral de acumulação capitalista, permitem afirmar que existe uma "questão agrária de fronteira" no Brasil.

A ausência do Estado se constitui numa característica típica da fronteira que está relacionada à existência de ilegalidades diversas, fazendo desse espaço “terra sem lei", lugar de perigo, contravenções diversas, sobretudo na apropriação de terras e recursos naturais. A ausência do Estado também deixa caminho livre para a prática de exploração e violência contra camponeses, indígenas, trabalhadores, etc.

Martins (1996), ao interpretar a fronteira sob a perspectiva sociológica, destaca que a ausência do Estado abre possibilidade para a presença da dominação pessoal, violência e repressão, ou seja, “[...] lugar que, na ausência expressa e direta do Estado, pauta grande parte das relações pela dominação personalizada, mediante forças repressivas do privado". (MARTINS, 1996, p. 40)

Essa compreensão pode ser cotejada com declarações de agentes de pastoral e bispos da Igreja Católica que atuam na fronteira amazônica, os quais pedem a presença da lei e do Estado. Os agentes reclamam a presença das instituições governamentais para garantir o "estado de direito" em vista da violência e exploração praticadas por grileiros, latifundiários e madeireiros a fim de ampliar suas posses.

Segundo a CPT (Comissão Pastoral da Terra), no Estado do Pará, ocorreram 914 assassinatos de trabalhadores rurais, religiosos e advogados por questões de terra no período de 1964 e 2010. Destacam-se dentre as violências recentes praticadas nessa fronteira as ameaças de morte a agentes de pastoral e lideranças de reservas extrativistas como Laísa Sampaio e Zé Rondon; o assassinado, em 2011, de Zé Cláudio e Maria Espírito Santo, do Projeto de Assentamento Praia Alta, no município de Nova Ipixuna (PA), na denominada Terra do Meio.

A ausência do Estado deixa vulneráveis camponeses, indígenas, agentes de pastoral e trabalhadores à força do poder econômico e político que impõe a sua lei. Assim, ao contrário de liberdade democrática da fronteira com a ausência do Estado, como enfatizou Turner (2004), verificam-se violências, degradação humana e barbáries diversas que se constituem num expediente da acumulação de capital. Tais violências, degradação humana e barbáries típicas do espaço agrário de fronteira estão articuladas ao processo geral de acumulação capitalista.

Outra característica típica do espaço agrário de fronteira é a apropriação ilegal de terras, que também faz parte do processo geral de acumulação capitalista e está presente des- 
de o passado distante. É exemplar a apropriação irregular de terras na "frente pioneira" paulista a partir do início do século XX. Muitas terras atualmente legalizadas têm passado de ilegalidade e irregularidade na sua apropriação.

Monbeig (1984), ao tratar da "frente pioneira" com a ocupação territorial do Estado de São Paulo, descreve os diversos ardis utilizados pelos proprietários para comprovar apropriação e "esquentar" documentação "fria" da propriedade da terra.

As medidas legais de 1895 e 1900, exigindo a apresentação de documentos antigos, sugeriam a possibilidade de os forjar. Os falsários deram provas de imaginação e habilidade diabólicas: buscaram folas de papel timbrado com as armas imperiais, imitaram escritas fora de uso, descolaram velhos selos, amareleceram propositalmente seus documentos, arrancaram páginas de registros de tabeliães... Toda a zona pioneira em São Paulo como no Paraná conheceu os grileiros e as práticas do grilo... Ficaram famosos como os da Alta Sorocabana, os do vale do Aguapeí ou ainda os do Sertão de Rio Preto. (MONBEIG, 1984, 144/155)

Nesse contexto, é possível citar muitos exemplos de apropriação ilegal de terras como aquelas ocorridas no Pontal do Paranapanema, estudado por Leite (1998); no Noroeste Paulista, em especial o município de Jales, estudado por Nardoque (2011), dentre outros. A apropriação ilegal de terras contribui para explicar a existência de área de terras devolutas em todo o Brasil, sobretudo nas fronteiras.

Segundo Oliveira (2011), utilizando-se de dados do Incra, existem 404.970.000 hectares de terras devolutas, ou seja, 47,6\% da área total do país. Mas, tais glebas estão apropriadas privadamente por grandes proprietários de terra. Acrescenta-se a esse contexto de apropriação de terras a participação de empresas estrangeiras, o que não se constitui fato novo no Brasil.

As terras públicas apropriadas ilegalmente se constituem num estoque que pode ser utilizado para a realização da reforma agrária. Embora a correção do índice de produtividade seja uma demanda dos movimentos sociais para a formação de um estoque de terras para a reforma agrária, ele já existe. Aliás, a reforma agrária não anda no Brasil, como será abordado posteriormente.

Se num primeiro momento é recorrente na fronteira a apropriação ilegal de terras, num segundo momento surge o expediente da legalização e reconhecimento oficial da apropriação das terras. A regularização da apropriação de terras propostas pelo governo federal por meio de edição de MPs (medidas provisórias), como a MP do Bem (2005), a MP 422 (2008) e a MP 458/2009, é exemplo desse processo. Conforme discurso governamental, motivado pela necessidade de regularização de áreas de posseiros, foram baixadas 
MPs propondo a "regularização fundiária" de 157 mil ocupações, abrangendo uma área de 67,4 milhões hectares de terras devolutas, no limite de 1.500 hectares, na Amazônia Legal.

A CPT emitiu nota pública em 2009 denunciando a oficialização da grilagem de terra na Amazônia com a aprovação pelo Senado e Câmara Federal da MP 458/2009, a partir da iniciativa do Poder Executivo.

\begin{abstract}
Desta forma, a MP 458, agora às vésperas de ser transformada em lei, regulariza posses ilegais. Beneficia, sobretudo, pessoas que deveriam ser criminalmente processadas por usurparem áreas da reforma agrária, pois, de acordo com a Constituição, somente 7\% da área ocupada por pequenas propriedades de até 100 hectares (55\% do total das propriedades) seriam passíveis de regularização. Os movimentos sociais propuseram que a MP fosse retirada e em seu lugar se apresentasse um Projeto de Lei para que se pudesse ter tempo para um debate em profundidade do tema, levando em conta a função social da propriedade da terra. O governo, entretanto, descartou qualquer discussão com os representantes dos trabalhadores do campo e da floresta. (CPT, 2009, p.1)
\end{abstract}

Derivado de diversas MPs, como as citadas anteriormente, o governo elaborou em 2010 o Programa Terra Legal, que dispensa de licitação a aquisição de terra até 15 módulos fiscais. Dependendo da região, a área pode chegar a 1.500 hectares, embora a Constituição de 1988 estabeleça um máximo de 50 hectares. Segundo Teixeira (2011), o Programa Terra Legal não está alcançando êxito porque ele visa regularizar posses mansas e pacíficas numa realidade fundiária marcada pelos conflitos e ilegalidades na apropriação da terra.

\footnotetext{
Considere-se, em especial, o caráter declaratório do Cadastro do Incra, o que, no caso do Norte (ou da Amazônia), pode ter estimulado "corrida declaratória" nos últimos anos pelas expectativas geradas pelas ações (ou promessas) federais de regularização fundiária na região. A propósito, conforme se previa, ressalvadas as controvérsias políticas do Programa Terra Legal, este não tem logrado eficácia até o momento por uma razão simples, afora as de natureza operacionais e de gestão: o instrumento pretende referendar posses sem litígio (mansas e pacíficas) em uma realidade fundiária forjada nos conflitos e desvios em todos os níveis. (Teixeira, 2011, p.2)
}

As áreas acima de 2.500 hectares, não comprovada a origem lícita da apropriação, podem ser retomadas pelo Estado. Mas, esse expediente de retomada de terras ilegalmente apropriadas por grandes proprietários, é de difícil execução porque tais proprietários possuem muita força política e impedem iniciativas que possam atingir seus interesses. A força política dos grandes proprietários rurais se expressa, sobretudo, por uma bancada no Congresso Nacional, a bancada ruralista, que se constitui numa espécie de "Partido da Terra", conforme destacou Castilho (2012). A bancada ruralista agrega parlamentares de diversos partidos para defender os interesses da oligarquia rural, habituada à acumulação patrimonial e rentista de capital. 
A acumulação rentista com a apropriação de terras para fins especulativos é outra característica do espaço agrário de fronteira. As terras apropriadas ou "griladas" não são necessariamente destinadas à produção de mercadorias, mas deixadas para "valorização", garantindo aos proprietários fundiários obtenção de lucro-extra ou um "superlucro" a partir da acumulação de renda da terra. É comum a aquisição de terra a "preço de banana" com objetivos comerciais, o que permite a acumulação de renda nas mãos dos setores proprietários. Nesse caso, verifica-se uma exploração rentista da terra que vai adiante da exploração produtiva, seja ela capitalista ou camponesa.

A existência de terras improdutivas indica que o rentismo ainda se constitui num recurso adotado pelos setores proprietários de terra para acumulação de capital. De acordo com Teixeira (2011), no período de 2003 a 2010 houve diminuição das áreas produtivas de grandes propriedades de $37,7 \%$ para $28,3 \%$, indicando elevação da ociosidade da terra nas grandes propriedades. $\mathrm{O}$ aumento da área improdutiva das grandes propriedades ocorreu, sobretudo, na Amazônia ${ }^{3}$.

As grandes áreas de terras improdutivas também são verificadas no estudo de Oliveira (2011). Segundo o autor, conforme cadastro de imóveis do Incra, dos 851.487 .659 hectares de área total do país, 216.328.597 hectares são considerados improdutivos, somando 73.824 imóveis. Acrescenta-se a esses dados de improdutividade da terra a existência de 58,6 milhões de hectares de pastagens degradadas de baixa produtividade, conforme estudo da Embrapa feito por Assad (2013).

As terras dominadas pela agricultura empresarial em grandes propriedades de agronegócio também não apresentam índices satisfatórios de produção. Oliveira (2003) afirma que, embora o agronegócio tenha se dedicado às lavouras para o mercado externo, não é necessariamente sinônimo de elevada produtividade, pois a maior parte da produção agropecuária nacional está sob responsabilidade dos pequenos e médios agricultores. O aumento das terras improdutivas das grandes propriedades contrasta com a ideia de que as empresas rurais de agronegócio estão substituindo as propriedades latifundiárias improdutivas.

Acrescente ainda aos limites do agronegócio sua dependência de intervenções estatais de garantias políticas e econômicas, o que contrasta também com a ideia de eficiência produtiva das grandes propriedades. Dentre as garantias econômicas, os grandes proprietários, a partir das suas representações políticas, como a bancada ruralista, exigem cada vez mais do Estado financiamentos de custeio e investimento nos Planos Safra. Outras ga-

3 A Amazônia possui baixo índice de uso terra para atividade pecuária com uma média de uma cabeça de gado por hectare. 
rantias são demandadas pelos proprietários fundiários, como financiamentos a juros baixos, renegociação/rolagem de dívidas, alongamento de prazos, ampliação de carências e prorrogação de débitos de custeio.

Os grandes proprietários rurais exigem também melhoria na infraestrutura e logística para escoamento da produção agrícola, pois, segundo os representantes desse setor, um conjunto de problemas logísticos tem limitado a competitividade dos produtos de exportação do agronegócio brasileiro no mercado internacional. Esse é o caso da malha viária (ferrovias, rodovias e hidrovias), que dificulta o intercâmbio entre os terminais de movimentação de mercadorias; dos terminais graneleiros e portos que carecem de modernização e consolidação; dutos para expansão da produção de agrocombustível; infraestrutura de armazenamento que provoca a formação filas nos terminais de escoamento da produção; dentre outros problemas.

Além de garantias econômicas e ligadas à produção, o Estado também deve, de acordo com o setor ruralista, prover garantias políticas, pois os segmentos ruralistas estariam precisando de tranquilidade para produzir. Dentre as medidas políticas defendidas pelos ruralistas está o veemente combate à ação dos movimentos sociais no campo, em destaque para os indígenas e sem-terras. Segundo Xico Graziano (2007), as ocupações de terra, por exemplo, têm afugentado empresários que desejam investir na agricultura. $\mathrm{O}$ autor argumenta que as regiões onde os movimentos sociais têm forte atuação, como o Pontal do Paranapanema, houve uma regressão econômica nos últimos anos porque existe grande probabilidade das propriedades rurais serem invadidas (sic) pelos sem-terra contrários à modernização e ao progresso da agricultura brasileira.

Nesse sentido, os ruralistas têm demonstrado mais eficiência política do que econômico-produtiva. A atuação política por meio de seus representantes no Congresso Nacional, que formaram uma bancada ruralista, é um exemplo da força dos grandes proprietários rurais. A atuação da bancada ruralista em defesa dos segmentos proprietários de terra ocorre de diversas formas, como na flexibilização das leis ambientais, impedimento da correção do índice de produtividade, liberação de cultivo de sementes transgênicas, abertura de CPIs, impedimento à aprovação de legislação que coíbe trabalho escravo, combate à homologação e demarcação de terras indígenas, dentre outras.

Mas, existe também na fronteira uma acumulação típica do capitalismo, com a presença de uma exploração produtiva da terra que segue na esteira do capital especulativo e da apropriação ilegal de terras. Assim, verifica-se um cruzamento contraditório e desigual de investimentos capitalistas não-produtivos com investimentos capitalistas produtivos de mercadorias na fronteira. 
Os investimentos capitalistas produtivos ocorrem nas mais diversas atividades econômicas, dentre as quais se destaca a produção agrícola empresarial de agronegócio. Conforme Alentejano (2010), a partir de dados do IBGE, houve no Brasil um aumento da área de culturas de agronegócio de exportação (soja/cana/milho) em 17 milhões de hectares no período de 1990-2006. A madeira teve aumento de 47 para 101 milhões de metros cúbicos no período de 1990-2006. Se nas culturas de agronegócio houve aumento da área e volume de produção, a produção de feijão teve um decréscimo de 2,5 milhões de hectares. O gado, nesse período, passou de 147 para 202 milhões de cabeças, sobretudo com o aumento daquele que foi tocado para a Amazônia pelas lavouras de exportação.

Atualmente, os investimentos capitalistas produtivos contam com importante participação do Estado. O estímulo do Estado aos investimentos produtivos pode ser verificado no PAC (Programa de Aceleração do Crescimento), que procura criar condições para expansão de projetos hidrelétricos, amparados na concepção desenvolvimentista, ou neodesenvolvimentista, dos governos Lula e Dilma.

As medidas estatais do PAC para estímulo ao capital produtivo verificadas na construção de grandes obras hidrelétricas na Amazônia são componentes necessários para entendimento da questão agrária nessa fronteira, pois implicam na expropriação e expulsão de milhares de camponeses ribeirinhos e indígenas de suas terras. Apenas a hidrelétrica de Belo Monte, no Rio Xingu, deverá atingir 30 mil ribeirinhos, indígenas e quilombolas.

Estão previstas a construção de 28 grandes barragens nos rios da Amazônia nos próximos dez anos. No Rio Madeira estão sendo construídas as usinas de Jirau e Santo Antonio; no Rio Xingu, Belo Monte; no Rio Tapajós está prevista a construção de sete grandes barragens; além do complexo de usinas no Rio Teles Pires; dentre outras. A construção das hidrelétricas, segundo discurso governamental, é necessária para impedir um apagão de energia no país, bem como servir de base para o desenvolvimento da região amazônica. Mas, vários segmentos sociais organizados apontam que a energia não é para os pobres, e sim para atender às necessidades de mineradoras, siderúrgicas e grandes centros consumidores.

Outra característica típica do espaço agrário da fronteira, além da ausência do Estado, apropriação ilegal de terras e acumulação rentista, é a presença de trabalho escravo. $\mathrm{O}$ trabalho escravo na fronteira atinge, principalmente, aquele sujeito territorializado precariamente que se deslocou das áreas "consolidadas" do capitalismo no Centro-Sul, por exemplo, ou seja, aquele sujeito meio errante, transeunte, o "peão do trecho", que possui forte trajetória de mobilidade espacial. Esses sujeitos são aliciados quase sempre para trabalhar nas fazendas para derrubada das matas e formação de pastagem. 
O trabalho degradante análogo à escravidão se constitui numa relação não tipicamente capitalista que se reproduz contraditória e desigualmente na fronteira e serve a acumulação capitalista. A CPT, que publica anualmente os Cadernos dos Conflitos no Campo no Brasil, aponta numerosos casos de trabalho escravo praticados pelos proprietários fundiários e empresas que atuam na fronteira.

Embora tivesse estabilizado em 2012 por força da mecanização e fiscalização, a CPT contabilizou um total de 2.095 trabalhadores libertos em 2012 (em 2011 foram 2.077 trabalhadores libertos). O número de ocorrências de trabalho escravo no campo caiu de 230 em 2011 para 170 em 2012. O predomínio de ocorrências foi na Amazônia Legal, com 111 casos e 1.237 trabalhadores libertos.

\footnotetext{
Só no Pará, que lidera o ranking, foram registradas 49 ocorrências, com 540 trabalhadores libertos. Na sequência vem o Tocantins, com 321 libertos, e o Paraná, com 225. De acordo com a Pastoral da Terra, chama a atenção o fato de todos os Estados do Sul e do Sudeste terem registrado ocorrências. (Humanitas, 2013, p. 1)
}

Reconhecendo e procurando erradicar a existência de trabalho escravo no Brasil, o governo federal elaborou em 2003 o Plano Nacional Para Erradicação do Trabalho Escravo, vinculado ao Ministério do Trabalho, quando foi criada a Comissão Nacional para Erradicação do Trabalho Escravo (Conatrae). Foi elaborado um cadastro de propriedades rurais que utilizam o trabalho escravo, denominado pelas entidades ligadas aos direitos humanos e lutas camponesas de "lista suja" do trabalho escravo no Brasil, que é encabeçada por empresas do setor madeireiro, pecuário, extrativo de carvão, desmatamento e plantações de cana e soja. Mas, o ministro Ricardo Levandowski do STF (Superior Tribunal Federal), mesmo em período de recesso de Natal de 2014, deferiu uma liminar determinando a suspensão da publicação do cadastro de empregadores flagrados com trabalho escravo.

Na Câmara dos Deputados está tramitando desde 2001 a PEC (Proposta de Emenda à Constituição) 438/2001, que altera o artigo 243 da Constituição e prevê expropriação de propriedades rurais e urbanas onde for encontrado trabalho escravo. Após aprovação na Câmara em 2012, a PEC retornou ao Senado (no Senado é a PEC 57A/99) para "ajustes" ao conceito de trabalho escravo e até os dias atuais a PEC ainda não foi aprovada. Aliás, o conceito de trabalho escravo, embora já estivesse definido pela OIT (Organização Internacional do Trabalho) e principalmente no Código Penal (artigo 149) do Brasil, fundamenta o principal argumento da bancada ruralista para descaracterizar a escravidão contemporânea. 
Além daquelas características do espaço agrário da fronteira destacadas anteriormente, outra emerge como componente desse espaço: as resistências de camponeses e indígenas. Se na fronteira existe um sujeito meio errante, o "peão do trecho", muitos dos quais são vítimas de variadas formas de violência, facilitada pela ausência do Estado, existe também um sujeito (camponeses e indígenas) organizado, sobretudo nos movimentos sociais e sindicais, que realizam importantes lutas de resistência e negação à expropriação/expulsão ou lutas de conquista da terra.

As lutas de indígenas e camponeses não são recentes na fronteira do Brasil, mas ressurgiram e se fortaleceram com o esgotamento político e econômico do governo dos militares. Notabilizaram-se nesse contexto as lutas dos posseiros, indígenas, povos da floresta, pequenos agricultores atingidos pela construção de grandes obras, como foi o caso da construção da Hidrelétrica de Itaipu na fronteira do Brasil com o Paraguai. Naquele contexto de resistência e reivindicação de indenização justa das terras atingidas pela formação do Lago de Itaipu ressurgiram movimentos sociais camponeses no Brasil, silenciados pela força violenta da ditadura militar iniciada em 1964.

Emergiram também nessa conjuntura as resistências e lutas dos camponeses expropriados e despossuídos da terra que formaram o Movimento dos Trabalhadores Rurais Sem Terra (MST). A partir da década de 1980, o MST tornou-se o principal movimento camponês de resistência e luta pela reforma agrária no Brasil, combatido pelos setores dominantes com dura violência, como a que resultou nos massacres de Corumbiara (RO), em 1994, e Eldorado dos Carajás (PA), em 1996, dentre outros. Os povos indígenas que sempre foram duramente atingidos pela violência e expulsão de suas terras, nos dias atuais fazem forte enfrentamento à expansão territorial do agronegócio ou construção de grandes obras infraestruturais para o capital.

As lutas nos movimentos sociais permitiram aos camponeses alcançarem muitas conquistas, dentre as quais se destaca a terra. Nesse contexto, os movimentos sociais se firmaram como paradigmáticos e centrais nas lutas e resistências. A centralidade dos movimentos é verificada inclusive no fato de serem educativos, pois no processo de luta os sujeitos aprendem a reconhecer o opressor, se organizar e participar. A participação nos movimentos permite que pessoas adormecidas para a vida política despertem - permite, enfim, a emancipação social, política e econômica dos sujeitos.

Nesse contexto de fortalecimento e protagonismo dos movimentos sociais no campo emergiu certa "institucionalização", sobretudo a partir da década de 1990, quando os movimentos passaram a apresentar uma dimensão orgânica mais forte de vínculos de "dire- 
ção" e "base". Uma estrutura de organização se fortaleceu com a formação de secretarias regionais, estaduais, nacional e até internacional, com hierarquias, formação política, equipamentos, etc. Esse foi o caso do MST e da Via Campesina, por exemplo.

Ricci (2009) entende que os movimentos sociais surgidos nas décadas de 1970 e 1980 possuem substanciais diferenças em relação aos movimentos contemporâneos, não sendo possível, inclusive, entender os movimentos contemporâneos com os instrumentais teóricos da década de 1980. O autor afirma que muitos movimentos sociais que possuíam o objetivo de lutar por direitos, aumentando o poder da sociedade civil, tornaram-se organizações sociais, caracterizadas pela existência de hierarquias, orçamento, sede administrativa, etc.

Segundo Ricci (2009) ainda, na década de 1980, os movimentos questionavam a institucionalidade. Já nos dias atuais, eles vêem-se incorporados à estrutura institucional, sendo que muitas de suas lideranças estão inseridas nos governos. Essa prática não apenas intensificou a institucionalização, mas fez avançar a estatização e ações pragmáticas e centralizadoras, trazidas das experiências sindicalistas. Nesse sentido, Ricci (2009) afirma também que, resultante dessa relação com o Estado, sobretudo a partir do governo Lula, as organizações populares perderam a sua capacidade de formulação política, pois foram engolidas pela dimensão estatal e pelos parlamentos, diminuindo a energia dos movimentos. Por isso, conforme o autor, a era dos movimentos sociais calcada no ideário da participação e da decisão política tomada na base, tal como surgido na década 1970, teria acabado.

As mudanças ocorridas nas ações dos movimentos sociais estão inseridas no contexto de transformações e surgimento de novas demandas e reivindicações da sociedade civil organizada. Essas mudanças fizeram os movimentos redefinirem suas reivindicações, pautas, temas e método de luta. Nesse sentido, não se trata de fim da era dos movimentos, mas de redefinições em vista de novas conjunturas políticas e econômicas.

A relação dos movimentos com o Estado passou por redefinições, pois, se no passado esse era visto como adversário e inimigo das lutas, agora é considerado, em determinados aspectos, parceiro. Um exemplo de mudança na relação dos movimentos com o Estado nos dias atuais, se comparado ao seu ressurgimento no final da década de 1970, é o caso que envolve a Hidrelétrica de Itaipu. Atualmente, os camponeses à margem do Lago de Itaipu, ao invés de fazer enfrentamento à hidrelétrica, como ocorria no passado, estabelecem parcerias diversas, por meio de projetos de conservação, educação ambiental e de geração de renda, como o Programa Cultivando Água Boa, o Condomínio de Biodigestores da Linha Ajuricaba, dentre outros. Nesse contexto de parceria, os camponeses têm alcançado alguns benefícios de ordem econômica, social e ambiental que não devem ser desprezados. 
Os movimentos, na sua trajetória, acumularam experiências de lutar quando o governo é “inimigo". Porém, o fato de os governos Lula e Dilma estarem mais próximos dos movimentos colocou uma nova situação: se o movimento ataca o governo, fortalece os setores conservadores de direita; se alivia, não alcança conquistas maiores como a reforma agrária, por exemplo. Portanto, existe dificuldade para os movimentos colocar a reforma agrária na agenda do governo Dilma, apesar de o discurso governamental recente enfatizar o fortalecimento dos assentamentos, com o Programa Terra Forte, uma vez que, de acordo com o ex-ministro da Secretaria-Geral da Presidência da República, Gilberto Carvalho, "há muitos assentamentos que se transformaram quase em favelas rurais".

Desse modo, a reforma agrária não avança no país. O ano de 2012, conforme dados divulgados pelo Incra, foi o ano de menor realização de desapropriações para reforma agrária desde 1995, pois foram desapropriados somente 28 imóveis. No caso dos assentamentos houve forte diminuição do número de famílias assentadas, se comparado com os governos FHC e Lula. A média de famílias assentadas ao ano no governo Lula foi 76.761 e no governo FHC foi 67.588. O governo Dilma assentou apenas 22.552 famílias em média ao ano. Acrescenta-se ainda que uma parte expressiva dos assentamentos foi feita na Amazônia, pois as terras mais próximas dos centros consumidores (Sul do Brasil, por exemplo) são destinadas ao agronegócio. Cerca de 70\% das terras divididas aos camponeses estão localizadas na Amazônia e somente 9\% no Centro-Sul, embora esta região seja aquela onde se registram maior número de ocupações (90\% das ocupações de terra estão no Centro-Sul do Brasil).

Outra dificuldade vivida por alguns movimentos sociais camponeses, mas em menor proporção, é a compreensão do conflito da estrutura de classes que está colocado no campo nos dias atuais. A “direção" dos movimentos sociais entende que é o agronegócio, e não mais o latifúndio, o principal inimigo da reforma agrária a ser combatido. Esse é o caso do MST, por exemplo.

[...] agora mudou a correlação de forças políticas. Temos um inimigo mais poderoso. Agora, além do latifundiário, temos de enfrentar o modelo do agronegócio que representa uma aliança entre os grandes proprietários de terra, o capital estrangeiro e o capital financeiro. E some-se a eles o apoio ideológico irrestrito da grande mídia, que ataca permanentemente quando qualquer trabalhador se mobiliza. (STÉDILE, 2011, p. 2)

Os movimentos camponeses e muitos estudiosos a eles vinculados entendem que as grandes propriedades de agronegócio, embora tivessem se tornado sinônimo de produtividade, são promotoras da miséria, degradação ambiental, violências e outras barbáries. Assim, se o latifúndio excluía pela improdutividade, agora o agronegócio exclui pela pro- 
dutividade. Partindo desse pressuposto, o agronegócio se fortaleceu e os latifúndios, improdutivos, foram perdendo importância no campo brasileiro.

Essa interpretação do conflito no campo teve desdobramento na realização de ocupações de terra, pois estas ações são medidas eficazes para combater os latifúndios, mas não para combater o agronegócio. Para combater o agronegócio outras ferramentas de luta se fazem necessárias. A luta pela educação do campo, agroecologia e a "campanha permanente contra os agrotóxicos e pela vida" realizada pelos movimentos que compõem a Via Campesina, dentre outros, se inscreve nessas novas formas de enfrentamento ao capital. Trata-se de enfrentar o capital, o agronegócio, propondo alternativas e denunciando os prejuízos sociais e ambientais causados à população em geral. A luta por políticas públicas para os camponeses também emerge e toma força nesse contexto.

Embora recentemente o MST tenha revisto essa compreensão do capitalismo no campo e procurado recolocar o latifúndio em oposição à reforma agrária, o agronegócio ainda é visto como o principal inimigo a ser combatido, mesmo considerando que grande a maioria dos assentamentos de reforma agrária é realizada em terras latifundiárias e não em terras do agronegócio.

As dificuldades de mobilização do MST não se devem exclusivamente à "direção" com as redefinições dos vínculos que estabeleceram com o Estado ou compreensão do adversário da reforma agrária a ser combatido. Existe também uma dificuldade de "base", relacionada à mobilização "massiva”.

No caso dos sem-terra, essa dificuldade ocorre porque os sujeitos comparam a difícil vida num acampamento, quando as pessoas ficam expostas por longo tempo a violências, insalubridades, instabilidades, precárias condições de vida, dentre outras dificuldades, com a possibilidade de emprego urbano, mesmo que precário, dentro da denominada "política de pleno emprego" do governo federal. Comparam também a política de valorização do salário-mínimo e um sistema de proteção social com a vida dura no campo. Isso contribui para que o acampamento deixe de ser um atrativo como possibilidade de “inclusão” e emancipação dos sujeitos a partir da possível terra conquistada. Assim, as lideranças dos movimentos têm dificuldade de reunir grande número de famílias dispostas a realizar ocupações e montar acampamentos em terras latifundiárias.

Apesar das dificuldades de mobilização "massiva" de alguns movimentos, eles ainda possuem muita força e capacidade de lutas. O principal movimento social de luta pela reforma agrária é o MST, embora tenha emergido importantes ações daqueles movimentos que não constituíram estrutura organizativa, como o movimento dos indígenas e ribei- 
rinhos atingidos por grandes obras estatais de infraestrutura (usinas hidrelétricas). São exemplares as lutas dos atingidos pela barragem da hidrelétrica de Belo Monte no Movimento Xingu Vivo para Sempre.

Assim, apesar de se observar dificuldades de natureza "basista" e de "direção" para os movimentos sociais no campo, não é possível falar em crise estrutural, como se o paradigma estivesse esgotado ou como se a era dos movimentos sociais movidos pelo ideário da participação e decisão política de base tivesse acabado. Trata-se de nova condição para os movimentos sociais em vista da conjuntura econômica e política com a ascensão de governos "populares", embora esses não vislumbrem transformações estruturais no campo.

\section{CONSIDERAÇÕES FINAIS}

A partir das questões apontadas, é possível chegar a um conjunto de verificações. Partindo da perspectiva de que fronteira é um espaço de limite entre território, é possível concluir que existem fronteiras entre territórios nacionais ou internos à nação. A fronteira entre o território dos camponeses e indígenas e o território do agronegócio latifundiário pode ser um exemplo de fronteira interna à nação.

Verifica-se também que a fronteira é forjada no processo contraditório e desigual de expansão das relações capitalistas de produção, quando um processo geral se realiza num quadro territorial menor. Nesse quadro territorial menor existem características típicas desse espaço que interfere no processo geral de acumulação capitalista.

Dentre as características típicas da fronteira destacam-se a ausência do Estado, ilegalidade na apropriação de terras, utilização de terras para fins especulativos e acumulação rentista, trabalho análogo à escravidão, resistências e lutas camponesas e indígenas pela terra. Estas características típicas do espaço de fronteira permitem afirmar que existe uma "questão agrária de fronteira no Brasil". 


\section{REFERÊNCIAS}

1. ALENTEJANO, P.R.R. Questão agrária no Brasil: novas questões, velhos desafios. Porto Alegre: digitado. 2010.

2. ANDRADE, M. C. de. Geografia: Ciência da Sociedade. São Paulo: Atlas, 1987.

3. ASSAD, E. D. Agricultura de Baixa Emissão de Carbono: a evolução de um novo paradigma. www.eco.org.br. Acesso em 06/06/2013.

4. BRAY, S. C. Aspectos da trajetória teórico-metodológica da geografia agrária no Brasil. VIII ENGA. Barra dos Coqueiros: UFS, 1987.

5. BRASIL. IBGE. Censo agropecuário 2006. Brasília, 2006.

6. BRASIL. MDA. Referências para o desenvolvimento territorial sustentável. Brasília: NEAD, 2003. Série texto para discussão, n. 4.

7. CAMPOS, R. R. O Anarquismo na geografia de Élisée Reclus. Revista Geografia da UEG Goiânia, v.1, n.1, p. 1-26, jan./jun. 2012.

8. CASTILHO, A.L. Partido da Terra. São Paulo: editora contraponto. 2012.

9. CASTRO, A. B. Agricultura e desenvolvimento no Brasil. In: Ensaios sobre a econômica brasileira. Vol. 1. Rio de Janeiro: Forense, 1977. p. 77-146.

10. CERON A. O.; GIRARDI, L. H. O. Geografia agrária e metodologia de pesquisa. Boletim de Geografia Teorética, Rio Claro, v. 9, n. 17, p. 59-69, 1979.

11. CPT. Oficializada a grilagem da Amazônia: Nota Pública. Goiânia: CPT. Junho 2009.

12. DELFIM NETO, A. Nota sobre alguns aspectos do problema agrário. In: Problemas econômicos da agricultura brasileira. São Paulo: FEA-USP, boletim n. 40, s. d., p. 1-73.

13. DINIZ, J. A. D. Geografia da Agricultura. São Paulo: Difel, 1984.

14. FOWERAKER, J. A Luta pela Terra. Rio de Janeiro: Zahar Editores S.A. 1982.

15. GEORGE, P. Geografia Econômica. Rio de Janeiro: Fundo de Cultura, 1965.

16. Geografia Rural. São Paulo: Difel, 1982.

17. GONÇALVES NETO, W. Estado e Agricultura no Brasil. São Paulo: Hucitec. 1997.

18. GRAZIANO NETO, F. O Carma da Terra no Brasil. São Paulo: A Girafa, 2004.

19. GUSMÃO, R. P. Os estudos de geografia rural no Brasil: revisão e tendências. Campo-território: revista de geografia agrária, v. 1, n. 2, p. 3-11, ago. 2006.

20. HAESBAERT, R. Descontrole dos Territórios (e de suas Fronteiras) num Mundo Globalizado. Geografia em Questão Agrária. M.C. Rondon. V.1, n. 2. p. 56-69. 2009.

21. HUMANITAS. Freado por mecanização e fiscalização, trabalho escravo é reduzido no campo. www.humanitas.com.br. Notícias. Acessado em 29 de abril de 2013. 
22. KROPOTKIN, P. O Estado e seu papel histórico. Trad. Alfredo Guerra. São Paulo: Imaginário. 2000.

23. LEITE, J. F. A Ocupação do Pontal do Paranapanema. São Paulo: Hucitec. 1998.

24. MARTINS J. S. Capitalismo e tradicionalismo. São Paulo, Pioneira. 1975.

25 . Camponeses e a política no Brasil. Petrópolis: vozes. 1981.

26. Expropriação e Violência. São Paulo: Hucitec. 1987.

27. Fronteira. São Paulo: Hucitec.1996.

28. MONBEIG, P. Pioneiros e fazendeiros de São Paulo. São Paulo: Hucitec, 1984.

29. NARDOQUE, S. A apropriação capitalista da terra e a formação da pequena propriedade em Jales/SP._Dourados: EDUFGD. 2011.

30. OLIVEIRA, A. U. Contribuição para o estudo da geografia agrária: crítica ao "Estado Isolado" de Von Thünen. Tese (Doutorado em Geografia), Faculdade de Filosofia, Letras e Ciências Humanas, Universidade de São Paulo, São Paulo, 1979.

31. Agricultura e Indústria no Brasil. BPG, São Paulo, n. 58, p. 05-64, set. 1981.

32. Agricultura camponesa no Brasil. São Paulo: Contexto, 1991.

33. Modo de Produção Capitalista, Agricultura e Reforma Agrária. São Paulo: Labur. 2007.

34. A questão agrária no Brasil. Brasília, Digitado. 2011.

35. PAIVA, R. M. Elementos básicos de uma política a favor da agricultura brasileira. Pesquisa e planejamento econômico, 4, p. 44-209, 1974.

36. PEREIRA, A. C. L. Garimpo e a Fronteira Amazônica. Dissertação de Mestrado. Belo Horizonte. UFMG, 1990.

37. PETRONE, P. Perspectiva da Colonização no Brasil. Anais da Associação dos Geógrafos Brasileiros, v. 18, p. 49-59, 1973.

38. SEABRA, M. As Cooperativas Mistas do Estado de São Paulo. São Paulo: Instituto de Geografia da USP. 1977.

39. TEIXEIRA, G. Agravamento do Quadro de Concentração da Terra no Brasil. Digitado. 2011.

40. TURNER, F. J. O Significado da Fronteira na História Americana. In: KNAUSS, P. (org.). O Oeste Americano: quatro ensaios de história dos Estados Unidos da América. Niterói: EDUFF. 2004.

41. VALVERDE, O. Estudos de Geografia Agrária Brasileira. Petrópolis: Vozes. 1985.

42. WAIBEL, L. Capítulos de Geografia Tropical e do Brasil. Rio de Janeiro: IBGE. 1979. 